\title{
Predicting the consequences of selecting on PrP genotypes on PrP frequencies, performance and inbreeding in commercial meat sheep populations
}

\author{
Wing-Young N. MAN ${ }^{\mathrm{a} *}$, Ronald M. LEWIS ${ }^{\mathrm{b}}$, Kay BOULTON ${ }^{\mathrm{c}}$, \\ Beatriz VILLANUEVA ${ }^{\mathrm{a}}$ \\ a Scottish Agricultural College, West Mains Road, Edinburgh, EH9 3JG, UK \\ ${ }^{\mathrm{b}}$ Department of Animal and Poultry Sciences (0306), Virginia Polytechnic Institute and State \\ University, Blacksburg, Virginia 24061, USA \\ ${ }^{\mathrm{c}}$ Meat \& Livestock Commission, Snowdon Drive, Milton Keynes, MK6 1AX, UK.
}

(Received 12 January 2007; accepted 6 June 2007)

\begin{abstract}
Selection programmes based on prion protein (PrP) genotypes are being implemented for increasing resistance to scrapie. Commercial meat sheep populations participating in sire-referencing schemes were simulated to investigate the effect of selection on PrP genotypes on ARR and VRQ allele frequencies, inbreeding and genetic gain in a performance trait under selection. PrP selection strategies modelled included selection against the VRQ allele and in favour of the ARR allele. Assuming realistic initial PrP frequencies, selection against the VRQ allele had a minimal impact on performance and inbreeding. However, when selection was also in favour of the ARR allele and the frequency of this allele was relatively low, there was a loss of up to three to four years of genetic gain over the 15 years of selection. Most loss in gain occurred during the first five years. In general, the rate of inbreeding was reduced when applying PrP selection. Since animals were first selected on their PrP genotype before being selected on the performance trait, the intensity of selection on performance was weaker under PrP selection (compared with no PrP selection). Eradication of the VRQ allele or fixation of the ARR allele within 15 years of selection was possible only with PrP selection targeting all breeding animals.
\end{abstract}

sire referencing / scrapie / prion / PrP selection / inbreeding

\section{INTRODUCTION}

Several countries are currently implementing breeding programmes for increasing resistance to scrapie $[1,6,7,9-12,28]$. In most of these programmes,

* Corresponding author: nicola.man@sac.ac.uk

SLS Group, SAC, Bush Estate, Penicuik, Midlothian EH26 OPH, Scotland, UK. 
selection is based on polymorphisms at codons 136, 154 and 171 of the gene encoding the prion protein $(\mathrm{PrP})$, which are associated with susceptibility to the disease [16]. These polymorphisms jointly define the PrP alleles. In general, these programmes aim at eliminating the VRQ allele and increasing the frequency of the ARR allele. The effectiveness of such breeding programmes for increasing the frequency of resistant alleles has been investigated in mainstream commercial e.g. [2,3,21,22] and numerically small breeds e.g. $[11,15,28]$. Four of the studies also assessed the impact of selection on $\operatorname{PrP}$ genotypes on inbreeding and genetic variability $[2,11,21,28]$.

Selection on PrP genotypes could, additionally, have negative consequences on genetic progress for other economically important traits and, potentially, on inbreeding in commercial populations. In the UK as well as in other countries, sire-referencing schemes (SRS) had been established for commercial sheep populations in order to allow comparisons across co-operating flocks. In SRS, genetic links are created among flocks by the sharing of some rams (reference sires). These connections allow for across-flock genetic evaluations creating a larger pool of candidates for selection. The objective of this study was to assess, through Monte Carlo computer simulation, the impact of various $\operatorname{PrP}$ selection strategies on changes in PrP allele frequencies, inbreeding and genetic gain in performance traits, in meat sheep populations typical of those participating in SRS.

\section{METHODS}

\subsection{Genetic model}

The trait under selection was a performance trait, such as lean growth, for which an infinitesimal model and a moderate heritability (0.25) were assumed. It was recorded in both sexes before selection for breeding. The PrP gene was assumed to have no direct impact on the trait and to be unlinked with genes that influence this trait.

\subsection{Breeding schemes}

The simulations modelled the operation of SRS in the three major meatproducing breed types in the UK, i.e. terminal sire, crossing sire and hill sheep [3,25]. Hill breeds are kept in harsh hill areas and the ewes usually breed for four lamb crops. Older ewes of these breeds are then moved to less harsh upland areas where they are crossed with longwool sires (crossing sires). 
Table I. Simulation parameters for terminal sire, crossing sire, and hill breeds.

\begin{tabular}{lccc}
\hline & Terminal sire & Crossing sire & Hill \\
\hline Number of flocks & 15 & 13 & 17 \\
Number of ewes per flock & $40-140$ & $30-90$ & $100-700$ \\
Total number of ewes per year & 1030 & 600 & 6800 \\
Percentage of within-flock sires replaced per year & 50 & 50 & 60 \\
Number of reference sires replaced per year & 3 & 2 & 2 \\
Number of reference sires used per year per flock & 3 & 2 & 2 \\
Percentage of ewes producing lambs from reference sires & 31 & 30 & 8 \\
Within-flock sire:ewe ratio & $1: 20$ & $1: 20$ & $1: 40$ \\
Generation interval & & & \\
$\quad$ Male & 3.0 & 2.8 & 2.2 \\
$\quad$ Female & 3.5 & 3.4 & 3.8 \\
$\quad$ Average litter size & & & \\
$\quad$ at birth & 1.7 & 2.2 & 1.5 \\
$\quad$ at weaning & 1.5 & 1.6 & 1.3 \\
\hline
\end{tabular}

The resulting crossbred ewes are usually mated in lowland areas to rams of terminal sire breeds, which have good carcass characteristics.

In general, SRS for terminal sire breeds were modelled as described by Lewis and Simm [18]. Simulations of crossing sire and hill breeds followed the same model, but with different inputs for genetic, reproductive, survival and flock parameters. Table I summarises the most relevant parameters used in the simulation of the three breed types.

Populations were simulated over a 30 year period. Sire referencing started in year six, after five years of random selection. Selection on PrP genotype started in year 16 , after ten years of sire referencing. Year $t=0$ will refer to the year PrP selection began, so that year $\mathrm{t}=-15$ will refer to the base population (in which all animals were unrelated), and year $\mathrm{t}=15$ will refer to the last year of the simulation.

Animals were assumed to reach reproductive maturity at about two years of age, and breeding animals were selected when they were about one year old. From $\mathrm{t}=-10$ (when sire referencing began) onwards, replacement ewes and rams were selected based on estimated breeding values (EBV) for performance obtained from best linear unbiased prediction (BLUP).

There was one mating season per year that lasted three oestrus cycles. The overall conception rate was about $90 \%$ for all breed types. Litter size was modelled as described by Lewis and Simm [18]. Survival rates at various ages (which included accounting for involuntary culling) were derived based on 
estimates of the proportion of males and females at various ages in UK populations.

Dams were only used within their flock of birth for a maximum of four (terminal sire) or five years (crossing sire and hill). About $25 \%$ of dams were replaced annually. Two types of sires were used: within-flock sires which were only used within the flock in which they were born, and reference sires which were used across all flocks when SRS was implemented (i.e. from $\mathrm{t}=-10$ onwards). In contrast to the scheme modelled by Lewis and Simm [18], only rams born within the scheme were used. Within-flock sires were used for a maximum of three (terminal and crossing sires) or two (hill) consecutive years. Fifty (terminal and crossing sires) or $60 \%$ (hill) of the within-flock sires were replaced annually with new rams. The sires to be replaced were chosen at random. There were no restrictions on selection of family members for replacement ewes and within-flock rams, but full-sibs and half-sibs were avoided in the selection of replacement rams for the reference sire team.

During the years of sire referencing $(t=-10$ to $t=15)$, a team of six (terminal sire), three (crossing sire) or two (hill) reference sires were used each year. In the terminal and crossing sire scenarios, reference sires were used for a maximum of two consecutive years. Three of the team of six reference sires (the three oldest sires in the team) were replaced every year in terminal sire breeds, and two (randomly chosen) of the team of three were replaced in crossing sire breeds. In hill breeds, reference sires were replaced every year.

In terminal sire breeds, ten ewes were artificially inseminated in their first oestrus cycle to each of three reference sires (drawn at random from the team of six) in every flock and year. In crossing sire and hill breeds, ten and sixteen ewes, respectively, were artificially inseminated in their first oestrus cycle to each of two reference sires in every flock and year. Natural mating was practised for within-flock sires. Surplus ewes (i.e. those not artificially inseminated with a reference sire) and all ewes in the second and third oestrus that failed to conceive in the first oestrus (including those that failed after artificial insemination with a reference sire) were mated to within-flock rams. The within-flock ram:(surplus) ewe mating ratio and the percentage of breeding ewes producing lambs from reference sires for each breed type are shown in Table I. All matings were at random.

\subsection{Initial frequencies of $\operatorname{PrP}$ alleles and selection strategies}

Initial (at $\mathrm{t}=0$ ) allele frequencies simulated were $0.05,0.30$ and 0.70 for ARR (recognised to be the allele conferring most resistance to classical 
scrapie) and $0.05,0.15$ and 0.30 for VRQ (the most susceptible allele). These were based on the ranges estimated by Eglin et al. [13]. The specific combinations of ARR and VRQ frequencies simulated are given in the results (see later). The other alleles ( $\mathrm{xxx}$ ) made up for the remainder segregating in the population.

The PrP selection strategies modelled were the following: (1) only animals with no VRQ allele could be used for breeding (strategy S1); (2) only animals with at least one ARR allele and no VRQ allele could be used for breeding (strategy S2); or (3) all animals could be used for breeding, but they were sequentially selected on their genotype using the following priority - ARR/ARR, $\mathrm{ARR} / \mathrm{xxx}, \mathrm{xxx} / \mathrm{xxx}$ (i.e. those without ARR or VRQ), ARR/VRQ, VRQ/xxx, and VRQ/VRQ (strategy S3). Within each of these strategies, different groups of breeding animals were targeted for PrP selection: (1) reference sires (strategies $S 1_{R}, S 2_{R}$ and $S 3_{R}$ ); (2) all sires, i.e. reference sires as well as within-flock sires (strategies $\mathrm{S} 1_{\mathrm{RW}}, \mathrm{S} 2_{\mathrm{RW}}$ and $\mathrm{S} 3_{\mathrm{RW}}$ ); or (3) all breeding animals, i.e. all sires and breeding ewes (strategies $\mathrm{S} 1_{\mathrm{RWD}}, \mathrm{S} 2_{\mathrm{RWD}}$ and $\mathrm{S} 3_{\mathrm{RWD}}$ ). The PrP genotype of all targeted animals was assumed to be known.

When applying PrP selection strategies, only new breeding animals (reference sires, all sires or all sires and breeding ewes, depending on the strategy simulated) were selected based on their PrP genotype and they were then subsequently selected on their EBV for the performance trait. For instance, when S3 was applied, the first animals selected were those with the ARR/ARR genotype. If the number of homozygous ARR was higher than that required to be selected for breeding then animals within the ARR/ARR group were chosen according to their EBV. Equivalently, animals with the highest EBV of those not carrying the VRQ allele (S1) or of those carrying at least one ARR allele and no VRQ allele (S2) were selected for breeding.

These strategies were compared to the scenario where there was no selection on PrP, but animals were selected on the performance trait EBV (NS). Comparisons were in terms of ARR and VRQ frequencies ( $f_{A R R}$ and $f_{V R Q}$, respectively) and rates of genetic gain (for the performance trait) and inbreeding. Average true breeding value for the performance trait $\left(\mathrm{G}_{\mathrm{i}}\right)$ and average inbreeding $\left(\mathrm{F}_{\mathrm{i}}\right)$ of animals born at each year $\mathrm{i}$ were computed. Rates of gain $\left(\Delta \mathrm{G}_{\mathrm{i}}\right)$ and inbreeding $\left(\Delta \mathrm{F}_{\mathrm{i}}\right)$ were obtained every year as $\Delta \mathrm{G}_{\mathrm{i}}=\mathrm{G}_{\mathrm{i}}-\mathrm{G}_{\mathrm{i}-1}$ and $\Delta F_{i}=\left(F_{i}-F_{i-1}\right) /\left(1-F_{i-1}\right)$, respectively. Annual rates between years $i$ and $j$ $\left(\Delta \mathrm{G}_{\mathrm{i}-\mathrm{j}}\right.$ and $\Delta \mathrm{F}_{\mathrm{i}-\mathrm{j}}$, where $\left.\mathrm{j}>\mathrm{i}\right)$ were obtained by averaging the individual annual rates. One hundred Monte Carlo replicates were run for each scenario. Values presented are the averages over all replicates. 


\section{RESULTS}

\subsection{Changes in frequency of the VRQ allele}

Changes in $\mathrm{f}_{\mathrm{VRQ}}$ for strategies $\mathrm{S} 1_{\mathrm{R}}, \mathrm{S} 1_{\mathrm{RW}}, \mathrm{S} 1_{\mathrm{RWD}}$ and $\mathrm{NS}$ are shown in Figure 1 for the three breed types when the initial $f_{\mathrm{VRQ}}$ was $0.05,0.15$ or 0.30 . Corresponding values for $f_{A R R}$ were $0.70,0.30$ and 0.05 but changes in $f_{V R Q}$ were unaffected by the initial value of $\mathrm{f}_{\mathrm{ARR}}$. As expected, there was no change in $f_{V R Q}$ when selection was only on performance (NS).

When PrP selection was only applied to reference sires (strategy $S 1_{R}$ ), the rate at which $f_{\mathrm{VRQ}}$ decreased in hill populations was about half that observed in the other two breed types since, proportionally, substantially fewer ewes were mated to reference sires in hill populations. At $t=10, f_{V R Q}$ was approximately half the initial $f_{\mathrm{VRQ}}$ in both terminal and crossing sire populations but only about $3 / 4$ of the initial $f_{\mathrm{VRQ}}$ in hill populations.

Changes in $f_{V R Q}$ were practically the same for terminal and crossing sire populations except in the first year of PrP selection where the decrease in $f_{V R Q}$ was larger in crossing sire scenarios, particularly with selection targeted to reference sires only $\left(\mathrm{S}_{\mathrm{R}}\right)$. This was due to the different proportion of reference sires retained in the two breeds and potentially carrying the VRQ allele at time $\mathrm{t}=1(1 / 3$ of the reference sire team was retained in the crossing sire and $1 / 2$ was retained in the terminal sire). In subsequent years, all sires in the reference sire team would already have been replaced with non-VRQ carrier sires, and $f_{V R Q}$ was very similar in both breed types.

In all breed types, when selection was on all sires $\left(S 1_{\mathrm{RW}}\right) \mathrm{f}_{\mathrm{VRQ}}$ halved after two years of PrP selection and then approximately halved every four years. None of the 100 replicates for those scenarios targeting only the sires (i.e. $S 1_{R}$ and $\mathrm{S} 1_{\mathrm{RW}}$ ) led to the loss of the VRQ allele from the population within the 15 years of selection. In the terminal sire simulations with initial $f_{V R Q}$ of 0.15 , $f_{V R Q}$ at $t=15$ ranged across replicates from 0.01 to 0.12 for $S 1_{R}$ and from $<0.01$ to 0.01 for $S 1_{\mathrm{RW}}$. Ranges were narrower for hill breeds due to their larger population sizes. Only $\mathrm{S} 1_{\mathrm{RWD}}$ led to the elimination of the VRQ allele (in all replicates) and that occurred within five years, once all old breeding ewes were replaced with ewes selected on their PrP genotype.

Selection intensity against the VRQ allele was the same under strategies $\mathrm{S} 1, \mathrm{~S} 2$ and $\mathrm{S} 3$, and changes in $\mathrm{f}_{\mathrm{VRQ}}$ under S2 and S3 (not shown) were very similar to those for $\mathrm{S} 1$. The results (not only in terms of allele frequencies but also in terms of inbreeding and genetic gain) for terminal and crossing sire populations were very similar across all scenarios. Given this similarity, only results from terminal sire and hill simulations will be presented henceforth. 

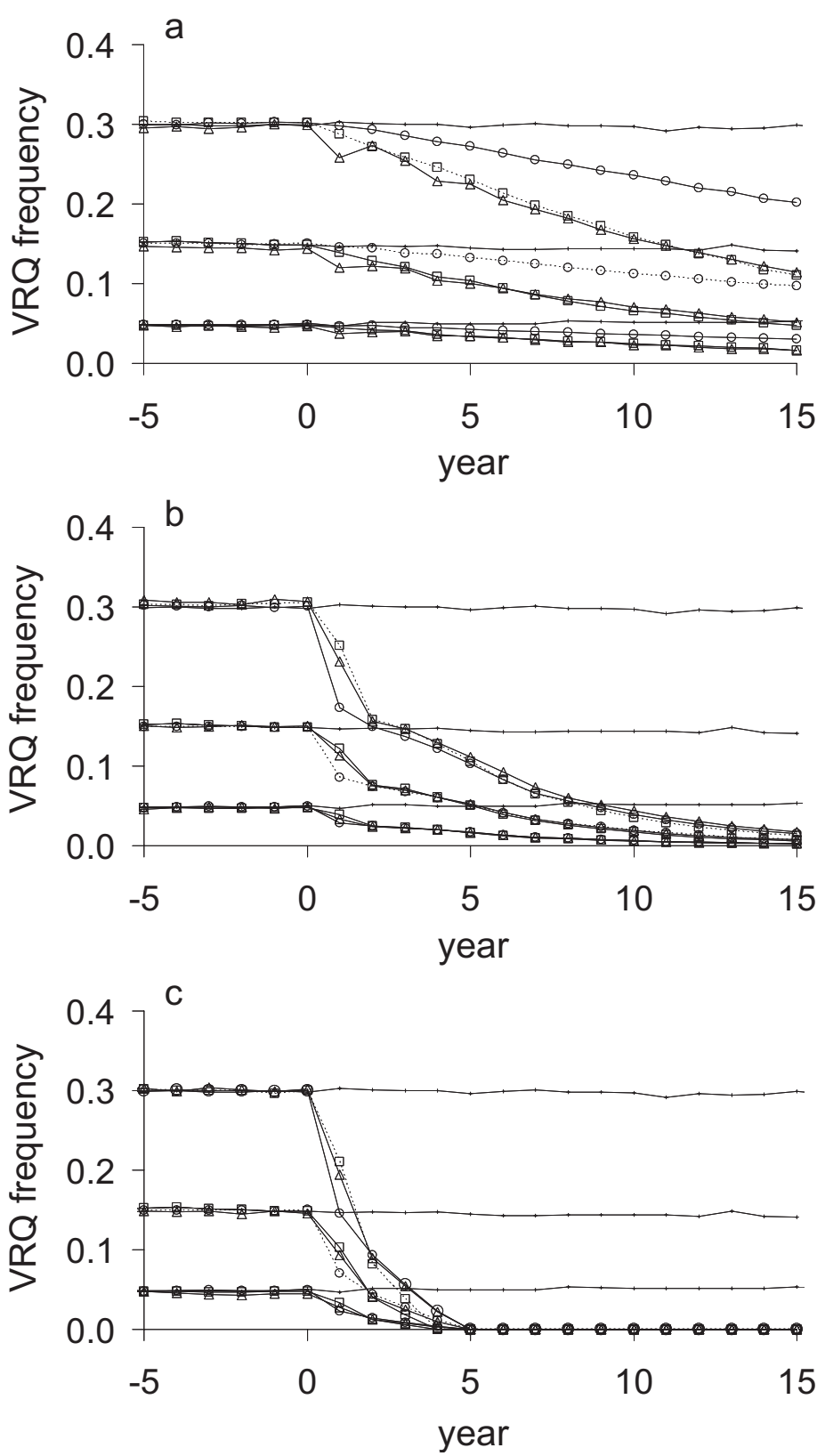

Figure 1. Frequency of the VRQ allele across years for terminal sire ( $\square$ ), crossing sire $(\Delta)$ and hill (o) breeds when there was no selection on PrP genotypes (.) and when strategy S1 (only VRQ non-carriers are used for breeding) was applied to reference sires $\left(S 1_{R}\right.$ in a), all sires $\left(S 1_{R W}\right.$ in $\left.b\right)$ or all breeding animals $\left(S 1_{R W D}\right.$ in $\left.c\right)$, for initial VRQ allele frequencies of $0.30,0.15$ and 0.05 . 


\subsection{Changes in frequency of the $A R R$ allele}

Figure 2 shows changes in $\mathrm{f}_{\mathrm{ARR}}$ under strategies $\mathrm{S} 2$ and $\mathrm{S} 3$ in terminal sire populations when the initial $f_{A R R}$ was $0.70,0.30$ or 0.05 . Corresponding values for $f_{V R Q}$ were $0.15,0.15$ and 0.30 . Strategy $S 1$ was ineffective at increasing $\mathrm{f}_{\mathrm{ARR}}$ and thus is not shown to simplify the presentation. Strategies $S 2_{\mathrm{RW}}$ and $\mathrm{S} 2_{\mathrm{RWD}}$ are not presented for the initial $\mathrm{f}_{\mathrm{ARR}}$ of 0.05 because some replicates failed due to a lack of a sufficient number of within-flock sires of the required genotypes.

Selection on reference sires only (Fig. 2a) or all sires (Fig. 2b) did not lead to fixation of the ARR allele within the 15-year time period. When the initial $\mathrm{f}_{\mathrm{ARR}}$ was 0.30 or higher, $\mathrm{f}_{\mathrm{ARR}}$ was midway between the initial frequency and fixation by year 3 and 10 of $\operatorname{PrP}$ selection with $S 3_{R W}$ and $S 3_{R}$, respectively, but only reached that point by year 11 with $\mathrm{S} 2_{\mathrm{RW}}$ and was still well below that point after 15 years with $S 2_{R}$. When the initial $f_{A R R}$ was 0.05 , the frequency reached only 0.50 at $\mathrm{t}=15$ with $\mathrm{S} 3_{\mathrm{R}}$ (and ranged from 0.34 to 0.65 across replicates) but was over 0.90 with $S 3_{\mathrm{RW}}$ (and ranged from 0.92 to 0.96 ).

When all breeding animals were targeted for PrP selection (Fig. 2c), the ARR allele reached fixation under strategy S3 by year 13, 10 and 7 when the initial $\mathrm{f}_{\mathrm{ARR}}$ was $0.05,0.15$ and 0.30 , respectively. Strategy $\mathrm{S} 2 \mathrm{did}$ not lead to fixation; at $\mathrm{t}=15 \mathrm{f}_{\mathrm{ARR}}$ was 0.85 (and ranged from 0.75 to 0.94 across replicates) and 0.92 (and ranged from 0.80 to 0.99 ) for initial values of 0.30 and 0.70 , respectively.

For hill sheep populations, changes in $\mathrm{f}_{\mathrm{ARR}}$ (not shown) were similar to those for terminal sire breeds when selection was on all sires or all breeding animals. However, ranges of $f_{A R R}$ across replicates were narrower, and in the first year of PrP selection, the frequencies changed more dramatically in hill populations (since there was a faster turnover of sires used). When selection was on reference sires only, changes in $f_{A R R}$ were slower in hill sheep populations than in other breed types (similar to that observed with changes in $\left.f_{V R Q}\right)$.

In summary, changes in allele frequencies (i.e. decrease in $f_{\mathrm{VRQ}}$ and increase in $f_{A R R}$ ) were much slower when selection was on reference sires only (compared with selection on all sires or on all breeding animals). Fixation of the ARR allele (with strategy $S 3_{\mathrm{RWD}}$ ) and eradication of the VRQ allele (with strategies $S 1_{\mathrm{RWD}}, \mathrm{S} 2_{\mathrm{RWD}}$ and $\mathrm{S} 3_{\mathrm{RWD}}$ ) within the 15 -year period was only possible when selection was on all breeding animals.

\subsection{Changes in genetic gain}

Table II shows annual rates of genetic gain in the performance trait and annual rates of inbreeding for terminal sire and hill populations under different 



Figure 2. Frequency of the ARR allele across years for terminal sire breeds when strategies S2 ( $\square$, only animals with at least one ARR and no VRQ are used for breeding) and $\mathrm{S} 3(\Delta$, all animals can be used for breeding, but they were sequentially selected on their genotype) were applied to reference sires $\left(S 2_{R}\right.$ and $S 3_{R}$ in a), all sires $\left(\mathrm{S} 2_{\mathrm{RW}}\right.$ and $\mathrm{S} 3_{\mathrm{RW}}$ in $\mathrm{b}$ ) or all breeding animals $\left(\mathrm{S} 2_{\mathrm{RWD}}\right.$ and $\mathrm{S} 3_{\mathrm{RWD}}$ in $\mathrm{c}$ ), for initial ARR allele frequencies of $0.70,0.30$ and 0.05 . 
Table II. Average annual rates of genetic gain in performance (in initial phenotypic standard deviation units) and inbreeding (in \%) over different time periods when different PrP selection strategies are applied on all sires in terminal sire and hill sheep populations ${ }^{1}$.

\begin{tabular}{|c|c|c|c|c|c|c|c|c|c|}
\hline & & \multicolumn{8}{|c|}{ Strategy $^{2}$} \\
\hline \multirow[t]{3}{*}{ Breed type } & & NS & S1 & S1 & S2 & $\mathrm{S} 2$ & S3 & S3 & S3 \\
\hline & & & & & $\mathrm{f}_{\mathrm{ARR}}=0.70$ & $\mathrm{f}_{\mathrm{ARR}}=0.30$ & $\mathrm{f}_{\mathrm{ARR}}=0.70$ & $\mathrm{f}_{\mathrm{ARR}}=0.30$ & $\mathrm{f}_{\mathrm{ARR}}=0.05$ \\
\hline & & & $\mathrm{f}_{\mathrm{VRQ}}=0.15$ & $\mathrm{f}_{\mathrm{VRQ}}=0.30$ & $\mathrm{f}_{\mathrm{VRQ}}=0.15$ & $f_{\text {VRQ }}=0.15$ & $f_{V R Q}=0.15$ & $f_{\text {VRQ }}=0.15$ & $\mathrm{f}_{\mathrm{VRQ}}=0.30$ \\
\hline \multirow[t]{6}{*}{ Terminal sire } & $\Delta \mathrm{G}_{1-15}$ & 0.135 & 0.134 & 0.131 & 0.133 & 0.130 & 0.132 & 0.122 & 0.106 \\
\hline & $\Delta \mathrm{G}_{1-5}$ & 0.137 & 0.136 & 0.129 & 0.136 & 0.127 & 0.132 & 0.103 & 0.074 \\
\hline & $\Delta \mathrm{G}_{6-15}$ & 0.134 & 0.133 & 0.132 & 0.131 & 0.132 & 0.132 & 0.131 & 0.122 \\
\hline & $\Delta \mathrm{F}_{1-15}$ & 0.58 & 0.56 & 0.52 & 0.56 & 0.55 & 0.52 & 0.53 & 0.45 \\
\hline & $\Delta \mathrm{F}_{1-5}$ & 0.59 & 0.55 & 0.49 & 0.55 & 0.54 & 0.48 & 0.46 & 0.27 \\
\hline & $\Delta \mathrm{F}_{6-15}$ & 0.58 & 0.56 & 0.54 & 0.56 & 0.56 & 0.56 & 0.57 & 0.54 \\
\hline \multirow[t]{6}{*}{ Hill } & $\Delta \mathrm{G}_{1-15}$ & 0.142 & 0.139 & 0.136 & 0.137 & 0.134 & 0.135 & 0.123 & 0.107 \\
\hline & $\Delta \mathrm{G}_{1-5}$ & 0.143 & 0.138 & 0.128 & 0.126 & 0.127 & 0.116 & 0.096 & 0.071 \\
\hline & $\Delta \mathrm{G}_{6-15}$ & 0.142 & 0.140 & 0.140 & 0.143 & 0.138 & 0.144 & 0.136 & 0.125 \\
\hline & $\Delta \mathrm{F}_{1-15}$ & 0.17 & 0.17 & 0.16 & 0.17 & 0.16 & 0.17 & 0.16 & 0.14 \\
\hline & $\Delta \mathrm{F}_{1-5}$ & 0.19 & 0.19 & 0.19 & 0.20 & 0.18 & 0.18 & 0.19 & 0.15 \\
\hline & $\Delta \mathrm{F}_{6-15}$ & 0.17 & 0.16 & 0.15 & 0.16 & 0.16 & 0.17 & 0.14 & 0.14 \\
\hline
\end{tabular}

${ }^{1}$ Standard errors for G ranged from 0.009 to 0.016 in terminal sire breeds and from 0.005 to 0.010 in hill breeds. Standard errors for F ranged from 0.03 to $0.07 \%$ in terminal sire breeds and from 0.02 to $0.05 \%$ in hill breeds.

${ }^{2}$ S1: only animals with no VRQ are used for breeding; S2: only animals with at least one ARR and no VRQ are used for breeding; S3: all animals can be used for breeding, but they were sequentially selected on their genotype.

selection strategies targeted to all sires. The results are summarised across the 15 years of PrP selection, for the first 5 years of selection and for the last 10 years of selection. When compared with the scenario where selection was only on the performance trait (NS), the reduction in genetic gain observed by selecting on PrP genotypes was very small with the strategy targeting only the VRQ allele (strategy $\mathrm{S} 1_{\mathrm{RW}}$ ) or that favouring ARR carriers (strategy $\mathrm{S} 2_{\mathrm{RW}}$ ); this was true even when $f_{V R Q}$ was relatively high (0.30) or $f_{A R R}$ was relatively low (0.30). Selection favouring homozygous ARR sires (strategy $\mathrm{S} 3_{\mathrm{RW}}$ ) also had a small impact on rates of gain for the performance trait when the initial $\mathrm{f}_{\mathrm{ARR}}$ was high $(0.70)$ but led to a substantial slowing in gain in both breeds when the initial $\mathrm{f}_{\mathrm{ARR}}$ was 0.30 or lower. Over the 15 years of selection, $\mathrm{S} 3_{\mathrm{RW}}$ led to about one and a half years (when initial $f_{A R R}=0.30$ ) or three years (when initial $\mathrm{f}_{\mathrm{ARR}}=0.05$ ) of loss in cumulative gain compared with that obtained with NS in terminal sire breeds. In hill breeds, equivalent cumulative losses in genetic gain were about two and four years for initial $\mathrm{f}_{\mathrm{ARR}}=0.30$ and $\mathrm{f}_{\mathrm{ARR}}=$ 0.05 , respectively. 
In general, the reduction in the rate of genetic progress was the greatest in the first five years of selection on PrP genotypes than in later years. For instance, under the scenario leading to the greatest reduction $\left(\mathrm{S} 3_{\mathrm{RW}}\right.$ with initial $\mathrm{f}_{\mathrm{ARR}}=0.05$ and $\mathrm{f}_{\mathrm{VRQ}}=0.30$ ) two of the three years (terminal sire) and two and a half of the four years (hill) lost in gain during the 15 year period occurred in the first five years.

As stated before, the results for crossing sires were very close to those for terminal sire breeds but they had higher standard errors due to their smaller population size.

\subsection{Changes in inbreeding}

The rate of inbreeding in scenarios undergoing PrP selection on all sires was equal to or less than the rate of inbreeding obtained with selection exclusively on the performance trait (Tab. II). In general, the greater the loss in genetic gain for the performance trait, the greater was the reduction in the rate of inbreeding. This is because selection on PrP genotype resulted in less intense selection on the performance trait, so that the animals selected for breeding tended to be less closely related than when selection was solely on the performance trait.

\subsection{Comparison of schemes targeting PrP selection at different groups of breeding animals}

Figure 3 shows average true breeding value and inbreeding plotted against $\mathrm{f}_{\mathrm{ARR}}$ for terminal sire populations with initial $\mathrm{f}_{\mathrm{ARR}}=0.30$ (the lowest frequency found in UK commercial breeds) and $f_{V R Q}=0.15$ (the highest frequency found in UK commercial breeds) when strategies S2 and S3 were targeted at reference sires only, all sires or all breeding animals.

Changes in gain and inbreeding with $\mathrm{f}_{\mathrm{ARR}}$ followed very similar patterns within each strategy. As expected, the smallest changes were in the scenarios targeting reference sires only and the largest changes were in the scenarios targeting all breeding animals.

The loss in gain was negligible when targeting reference sires only under strategy $\mathrm{S} 2\left(\mathrm{~S} 2_{\mathrm{R}}\right)$ but $\mathrm{f}_{\mathrm{ARR}}$ was just over 0.5 at the end of PrP-based selection $(\mathrm{t}=15)$. The results for strategy $\mathrm{S} 2$ targeting all sires $\left(\mathrm{S} 22_{\mathrm{RW}}\right)$ and for strategy $\mathrm{S} 3$ targeting reference sires $\left(\mathrm{S} 3_{\mathrm{R}}\right)$ were very similar. The losses in gain under these two strategies were small and $f_{A R R}$ increased up to 0.7 by $t=15$. The increase in $\mathrm{f}_{\mathrm{ARR}}$ was rapid in the initial years under strategy $\mathrm{S} 2$ targeted 

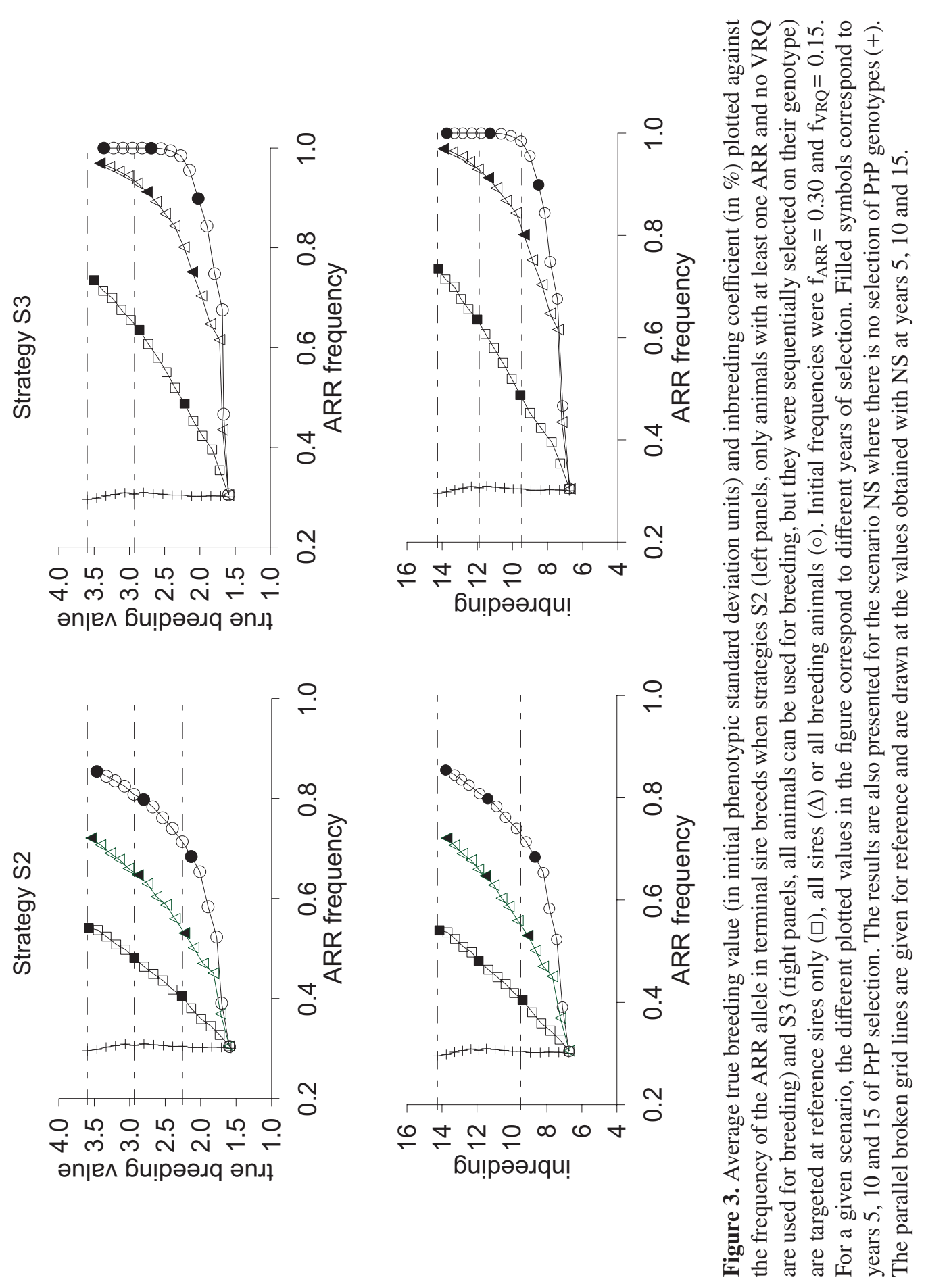
to all breeding animals $\left(\mathrm{S} 2_{\mathrm{RWD}}\right)$ and $\mathrm{f}_{\mathrm{ARR}}$ reached 0.85 at the end of the selection period. However, during the 15 years of PrP selection, this strategy led to about one year loss of cumulative gain when compared with NS and this loss occurred in the first five years. Strategy S3 targeted to all sires and to all breeding animals ( $S 3_{R W}$ and $S 3_{R W D}$ ) led to the fastest increases in $f_{A R R}$ (particularly $S 3_{\text {RWD }}$ which led to fixation by $t=10$ ) but also to the highest losses in rates of gain in the performance trait. For instance, during the 15 years of selection, $\mathrm{S} 3_{\mathrm{RWD}}$ led to loss of two years of cumulative genetic progress in performance when compared with NS and, as with other strategies, most of this loss occurred during the first five years.

Changes in $\mathrm{f}_{\mathrm{ARR}}$, and consequent changes in genetic gain for performance and in inbreeding, when applying S2 and S3 to different groups of breeding animals in hill sheep populations are shown in Figure 4. The results followed similar patterns to those obtained for terminal sire breeds except that when only reference sires were targeted for PrP selection, inbreeding increased with strategies $\mathrm{S} 2_{\mathrm{R}}$ and $\mathrm{S} 3_{\mathrm{R}}$ when compared with NS in hill breeds. Also, the similarity of results from strategies $S 2_{R W}$ and $S 3_{R}$ observed in terminal sire breeds was not observed in hill breeds.

\section{DISCUSSION}

This study investigated the impact of PrP selection on inbreeding and genetic gain in a performance trait in commercial populations already undergoing selection on EBV for that trait. It showed that, except under extreme PrP selection or low initial $\mathrm{f}_{\mathrm{ARR}}$, genetic gain would remain very similar to that obtained when selection is based only on performance in the main commercial breed types of sheep in the UK. Also, in general, rather than increase, the rate of inbreeding would decrease with selection on PrP genotypes when compared with the scenario where selection was based only on BLUP EBV.

A wide range of initial frequencies for the allele conferring the greatest resistance to classical scrapie (ARR) and for that conferring the greatest susceptibility (VRQ) were simulated. These ranges were determined based on estimates obtained from the National Scrapie Plan (NSP) in the UK [13]. The lowest NSP estimate of ARR frequency across the numerically large commercial breeds was about 0.30, and the highest estimate of the VRQ frequency was about 0.15 . Assuming these realistic frequencies for mainstream breeds, selection exclusively against the VRQ allele (S1), such as that currently being implemented through the NSP in the UK, is expected to have a minimal impact on rates of genetic gain and inbreeding. The impact of this strategy is 

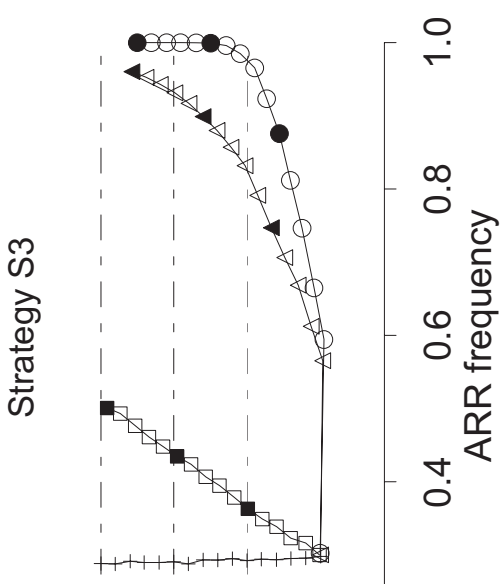

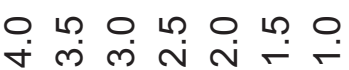
әпре би!рәәлq әпц

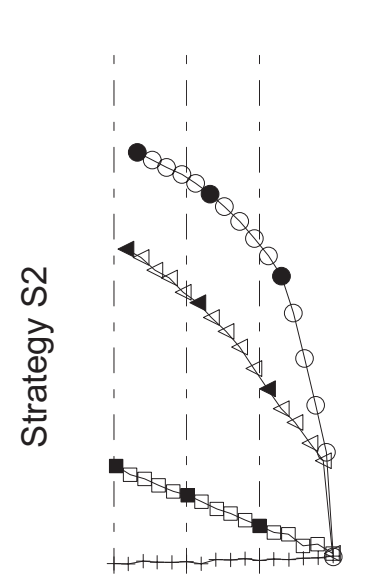

$\stackrel{\circ}{\circ}$

$\infty$

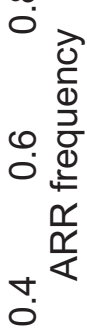

N

オ әпре би!рәәлq әnц

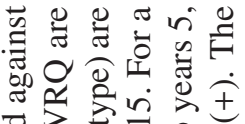

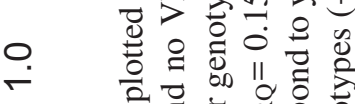

के ज्ञ

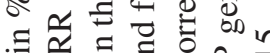

$\infty \quad \exists \frac{1}{0}$ है



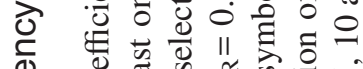

ग

○:

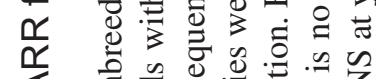

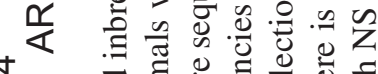

ナ. Z

ส 3 क्ष

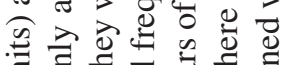

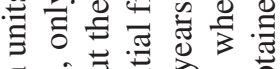

ㄴ.

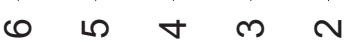

.\zh14्ञ би!рәәлqu!

ठै

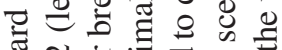
○. 苛 \%

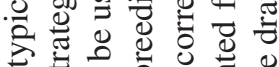

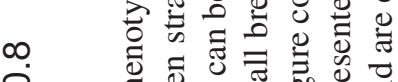

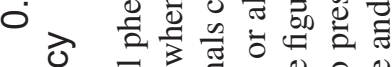
ठิ ข

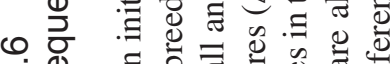

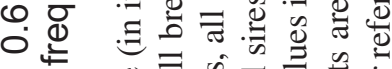

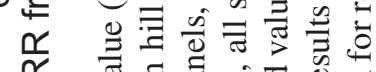

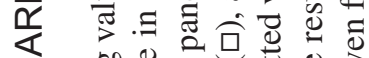
ナ. 屯 ปै

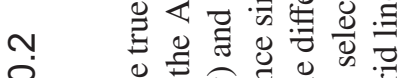
क्ष

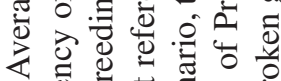
$+\stackrel{0}{0}$ 䒕

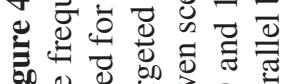
战 里 
also expected to be minimal with $\mathrm{f}_{\mathrm{VRQ}}$ as high as 0.30 . Strategies designed to increase the frequency of ARR and eliminate the VRQ allele (S2), such as those applied in France [7] are also expected to have a minimal impact on genetic gain unless not only sires but all breeding animals are targeted for $\operatorname{PrP}$ selection. However, more extreme strategies, such as those being applied in the Netherlands in favour of homozygous ARR/ARR [28], could lead to substantial losses in genetic gain for performance traits. The highest loss under strategy S3 was for hill breeds when the initial frequency of the ARR allele was low $\left(f_{A R R}=0.05\right)$. Up to four years in cumulative genetic gain were lost during the 15 years of PrP selection simulated when S3 was applied to all sires. Most of the reduction in gain in performance occurred in the first five years of PrP selection, when changes in frequencies were most dramatic.

The PrP gene was assumed not to be associated to the performance trait, which is reasonable since there has been no conclusive evidence so far for association between the PrP gene and performance traits e.g. [1, 6, 8, 17, 19, 24, 27]. Nevertheless, with an unfavourable linkage, a greater loss in genetic gain would be expected. The results for a favourable linkage would be expected to be similar to those for gene-assisted selection on a trait controlled by a quantitative trait locus and polygenes e.g. [26]. In this situation, there would be an increase in the rates of genetic gain (at least in the early generations of PrP selection) and inbreeding.

On the contrary to what was expected, selecting on PrP genotypes (in particular, to increase the frequency of the ARR allele) not only did not increase the rate of inbreeding but led, in general, to lower inbreeding rates than selecting exclusively on BLUP EBV. In a previous study where selection to increase performance was based on phenotypes rather than on BLUP EBV, inbreeding was unaffected when applying strategies $S 1_{\mathrm{RW}}, \mathrm{S} 2_{\mathrm{RW}}$ and $\mathrm{S} 3_{\mathrm{RW}}$ [20]. Reductions in the rate of inbreeding (compared with NS) depend on whether the increase in relatedness due to selection of breeding animals with the same genotype is offset by the decrease in relatedness due to a decrease in selection intensity on performance of the breeding animals. Our results contrast with those expected when there is no selection on performance. Windig et al. [28] simulated strategies comparable to $\mathrm{S} 2 \mathrm{RW}$ and $\mathrm{S} 3_{\mathrm{RW}}$ for rare breeds unselected for performance and found high increases in the rate of inbreeding as a consequence of increasing $f_{A R R}$ even when the initial frequency of this allele was as high as 0.70 . When selection is also based on performance, selection on PrP genotypes often implies a reduction in selection intensity for the performance trait, which results in lower rates of genetic gain and inbreeding. An exception was when strategies aimed at increasing $\mathrm{f}_{\text {ARR }}$ were targeted only to reference 
sires in hill breeds under BLUP selection, where inbreeding increased when compared with the scenario with no PrP selection. Under this scenario, selection intensity on performance did not decrease in any substantial way with $\operatorname{PrP}$ selection (hill breeds had larger population size and used less reference sires than terminal sire breeds) and selection of sires of the same genotype increased the rate of inbreeding.

Changes in PrP frequencies, although slower, were consistent with those found by Gama et al. [15], who simulated a strategy similar to S3 targeted to both rams and breeding ewes. Arnold et al. [3] and Roden et al. [22] analysed changes in PrP allele frequencies under strategies analogous to S1 and S2. However, their results are not directly comparable to the results found here since they considered the slaughter lamb population derived from crossbreeding of various types of breeds. Our results showed that, assuming realistic values for $f_{\mathrm{VRQ}}$, it would take around 7 to 12 years of selection against VRQ in sires for $f_{\mathrm{VRQ}}$ to fall below $1 \%$ in purebred populations participating in SRS. A longer time would be required for the slaughter lamb population to reach that level because of the stratified breeding structure of the sheep meat industry [22].

The changes in allele frequencies were quite similar across the three different breed types when all sires or all animals were selected on PrP genotypes. This implies that the effectiveness of the various PrP selection strategies is relatively robust to variation in the structural attributes of different breed types or populations. However, PrP selection on reference sires only was relatively sensitive to variation in population parameters such as age structure (which determines the generation interval). Thus changes in allele frequency (and also in rates of inbreeding and genetic gain) might be less predictable if only a small proportion of the population is selected on PrP genotype.

Fixation of the ARR allele was only achieved when PrP selection was targeted to all breeding animals. However, this strategy might not be advisable since, in addition to the concurrent reduction in genetic progress for performance traits and the high genotyping costs involved, fixation of the ARR allele is risky given the uncertainty surrounding scrapie $[4,5]$. A safeguard is to maintain the alternative alleles in an appropriately designed gene bank [14,23]. In general, strategies leading to faster increases in the frequency of the ARR allele also led to slower rates of gain in performance. To assess the efficacy of a scrapie eradication plan through genetic selection based on the PrP genotype, the models presented here could be extended to include epidemiological parameters for predicting the relative risk of occurrence of a scrapie outbreak in the population. 


\section{ACKNOWLEDGEMENTS}

This work was undertaken as part of a project funded by Defra (Department for Environment, Food and Rural Affairs, UK). In kind contributions to the project from the Meat and Livestock Commission, the Rare Breeds Survival Trust and the Sheep Trust are also acknowledged. SAC also receives financial support from SEERAD (Scottish Executive Environment and Rural Affairs Department). We thank S.C. Bishop, W.G. Hill, G. Nieuwhof, R.M. Sawalha and G. Simm for very helpful suggestions and comments.

\section{REFERENCES}

[1] Alexander B.M., Stobart R.H., Russell W.C., O’Rourke K.I., Lewis G.S., Logan J.R., Duncan J.V., Moss G.E., The incidence of genotypes at codon 171 of the prion protein gene (PRNP) in five breeds of sheep and production traits of ewes associated with those genotypes, J. Anim. Sci. 83 (2005) 455-459.

[2] Alfonso L., Parada A., Legarra A., Ugarte E., Arana A., The effects of selective breeding against scrapie susceptibility on the genetic variability of the Latxa Black-Faced sheep breed, Genet. Sel. Evol. 38 (2006) 495-511.

[3] Arnold M., Meek C., Webb C.R., Hoinville L.J., Assessing the efficacy of a ramgenotyping programme to reduce susceptibility to scrapie in Great Britain, Prev. Vet. Med. 56 (2002) 227-249.

[4] Baylis M., The Kafkaesque approach to scrapie control - A sense of impending danger, Vet. J. 173 (2007) 235-236.

[5] Baylis M., McIntyre K.M., Scrapie control under new strain, Nature 432 (2004) 810-811.

[6] Brandsma J.H., Janss L.L.G., Visscher A.H., Association between PrP genotypes and performance traits in an experimental Dutch Texel herd, Livest. Prod. Sci. 95 (2005) 89-94.

[7] Brochard M., Palhière I., Astruc J.M., Barillet F., Bouix J., Bibé B., Dion F., Elsen J.M., Francois D., Griffon L., Jullien E., Leymarie C., Orlianges M., Pantano T., Perret G., Tiphine L., Tribon P., Use of the PrP major gene to select for scrapie resistance: Example of the 5 years intensive French breeding plan, in: Proceedings of the 8th World Congress on Genetics Applied to Livestock Production, 13-18 August 2006, Belo Horizonte, CD-ROM communication no. 22-34.

[8] de Vries F., Borchers N., Hamann H., Drögemüller C., Reinecke S., Lüpping W., Distl O., Associations between the prion protein genotype and performance traits of meat breeds of sheep, Vet. Rec. 155 (2004) 140-143.

[9] Defra (Department for Environment, Food and Rural Affairs), http://www.defra.gov.uk/animalh/bse/othertses/scrapie/nsp/index.html [consulted: 05 June 2007].

[10] Detwiler L.A., Baylis M., The epidemiology of scrapie, Rev. Sci. Tech. Off. Int. Epiz. 22 (2003) 121-143. 
[11] Drögemüller C., de Vries F., Hamann H., Leeb T., Distl O., Breeding German sheep for resistance to scrapie, Vet. Rec. 154 (2004) 257-260.

[12] EC, Commission decision (2003/100/EC) of 13 February 2003 laying down minimum requirements for the establishment of breeding programmes for resistance to transmissible spongiform encephalopathies in sheep, Official Journal of the European Union, 14.2.2003, L41/41.

[13] Eglin R.D., Warner R., Gubbins S., Sivam S.K., Dawson M., Frequencies of PrP genotypes in 38 breeds of sheep sampled in the National Scrapie Plan for Great Britain, Vet. Rec. 156 (2005) 433-437.

[14] Fernández J., Roughsedge T., Woolliams J.A., Villanueva B., Optimisation of the sampling strategy for establishing a gene bank: storing PrP alleles following a scrapie eradication plan as a case study, Anim. Sci. 82 (2006) 813-822.

[15] Gama L.T., Carolino M.I., Santos-Silva M.F., Pimenta J.A., Costa M.S., Prion protein genetic polymorphisms and breeding strategies in Portuguese breeds of sheep, Livest. Sci. 99 (2006) 175-184.

[16] Hunter N., Molecular biology and genetics of scrapie in sheep, in: Piper L., Ruvinsky A. (Eds.), The Genetics of Sheep, CAB International, Wallingford, 1997, pp. 225-240.

[17] Isler B.J., Freking B.A., Thallman R.M., Heaton M.P., Leymaster K.A., Evaluation of associations between prion haplotypes and growth, carcass, and meat quality traits in a Dorset $\times$ Romanov sheep population, J. Anim. Sci. 84 (2006) 783-788.

[18] Lewis R.M., Simm G., Selection strategies in sire referencing schemes in sheep, Livest. Prod. Sci. 67 (2000) 129-141.

[19] Man W.Y.N., Brotherstone S., Merrell B.G., Murray W.A., Villanueva B., Analysis of association between PrP genotypes and live weight and slaughter traits in an experimental flock of Swaledale sheep in Great Britain, Anim. Sci. 82 (2006) 607-614.

[20] Man W.Y.N., Lewis R.M., Boulton K., Villanueva B. (2006) Genetic consequences of selecting on PrP genotypes on terminal sire and hill sheep breeds, in: Proceedings of the 8th World Congress on Genetics Applied to Livestock Production, 13-18 August 2006, Belo Horizonte, CD-ROM communication no. 04-05.

[21] Molina A., Juárez M., Rodero A., Merino sheep breed's genetic resistance to scrapie: Genetic structure and comparison of five eradication strategies, Prev. Vet. Med. 75 (2006) 239-250.

[22] Roden J.A., Nieuwhof G.J., Bishop S.C., Jones D.A., Haresign W., Gubbins S., Breeding programmes for TSE resistance in British sheep I. Assessing the impact on prion protein (PrP) genotype frequencies, Prev. Vet. Med. 73 (2006) $1-16$.

[23] Roughsedge T., Villanueva B., Woolliams J.A., Determining the relationship between restorative potential and size of a gene bank to alleviate the risks inherent in a scrapie eradication breeding programme, Liv. Sci. 100 (2006) 231-241.

[24] Sawalha R.M., Brotherstone S., Man W.Y.N., Conington J., Bunger L., Simm G., Villanueva B., Associations of polymorphisms of the ovine prion protein 
gene with growth, carcass and computer tomography traits in Scottish Blackface lambs, J. Anim. Sci. 85 (2007) 632-640.

[25] Simm G., Genetic improvement of cattle and sheep, 1st edn., Farming Press, 1998.

[26] Villanueva B., Pong-Wong R., Grundy B., Woolliams J.A., Potential benefit from using an identified major gene in BLUP evaluation with truncation and optimal selection, Genet. Sel. Evol. 31 (1999) 115-133.

[27] Vitezica Z.G., Moreno C.R., Bouix J., Barillet F., Perret G., Elsen J.M., A study on associations between PrP genotypes and meat traits in French sheep breeds, Anim. Sci. 81 (2005) 325-330.

[28] Windig J.J., Eding H., Moll L., Kaal L., Effects on inbreeding of different strategies aimed at eliminating scrapie sensitivity alleles in rare sheep breeds in The Netherlands, Anim. Sci. 79 (2004) 11-20. 